\title{
Carbamazepine Induced Stevens - Johnson Syndrome: A Case Report
}

\author{
Manjunath G, Sheetal N, Pooja S, Neelkantreddy P, Snehasri Y \\ Department of Pharmacy Practice, HKES MTRIPS, Gulbarga, Karnataka, INDIA.
}

\begin{abstract}
Stevens-Johnson syndrome is mucocutaneous cell mediated hypersensitivity reaction which affects 2 to 3 cases per million. SJS is generally rare, but potentially life threatening and commonly drug induced. We report a case of 12-year-old male child admitted to paediatric intensive care unit at a tertiary care hospital with chief complaints of fever, abdomen pain, vomiting erythematous lesions and macular rashes all over the body including face, neck, chest, both upper and lower limbs and abdomen. On the next day Bullous lesions were noted on the face and upper limbs, Conjunctivitis, Angioedema, Oral ulcers and blisters on angle of mouth were also observed. These signs and symptoms were started after taking Tab Carbamazepine $100 \mathrm{mg}$ on the 8th day. Based on the patient signs and symptoms the diagnosis was confirmed as Carbamazepine induced Stevens - Johnson syndrome. These Adverse drug reactions may lead to fatal organ failure and skin damage resulting in mortality. Pharmacovigilance which deals with the identification, assessment and prevention of ADRs can help in providing continuous information on medication safety use.
\end{abstract}

Key words: Adverse Drug Reaction, Carbamazepine, Stevens - Johnson syndrome.

\section{INTRODUCTION}

Adverse reactions, although rare, still remain a major threat to the patient welfare. StevensJohnson Syndrome (SJS) is one such fatal drug reactions. "A new eruptive fever with stomatitis and opthalmia" was described as a severe variant of erythema multiforme and was termed by Steven and Johnson in 1922. By the 1940's it was commonly called as "Steven Johnson's syndrome (SJS)". The concept of the spectrum of erythema multiforme has been widely accepted since that time. Although SJS is rare with an incidence of 0.05 to 2 persons per 1 million populations per year, it has significant impact on the public health in view of its high morbidity and mortality. ${ }^{1}$ Drug-induced dermatological reactions are common with the antiepiletic drugs such as carbamazepine (CBZ). These reactions may occur in the mild form as benign rash or may be severe and life-threatening as Erythema Multiforme Major or toxic Epidermal Necrolysis (TEN). Erythema multiforme major, also known as Stevens-Johnson Syndrome, is usually caused by reactions to medications, rather than infections. CBZ was originally introduced in therapeutic armamentarium as an anticonvulsant and is known to produce such adverse drug reaction (ADR), but the reports are rare. SJS is a blistering disorder, characterized by mucosal erosions at two or more sites with small blisters and purpuric macules. ${ }^{2}$ Here, we report a case of a 12 year old male child who developed carbamazepine induced Stevens-Johnson syndrome.

\section{CASE REPORT}

A 12 year- old male child was admitted to the Paediatric Intensive Care Unit at a tertiary care hospital with the chief complaints of erythematous, macular rashes all over the body including face, neck, chest, both upper and lower limbs and abdomen. History of present condition states that the patient had fever, pain abdomen and vomiting three
DOI: 10.5530/ijopp.11.3.35

Address for correspondence: Prof. Manjunath .G.Gandage Asst Prof, Department of Pharmacy Practice, H K E'S College of Pharmacy (MTRIPS), Sedam road, Gulbarga-585 104, Karnataka, INDIA.

Phone no: +9132326585

Email Id: mggandage@gmail.com

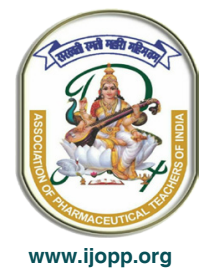




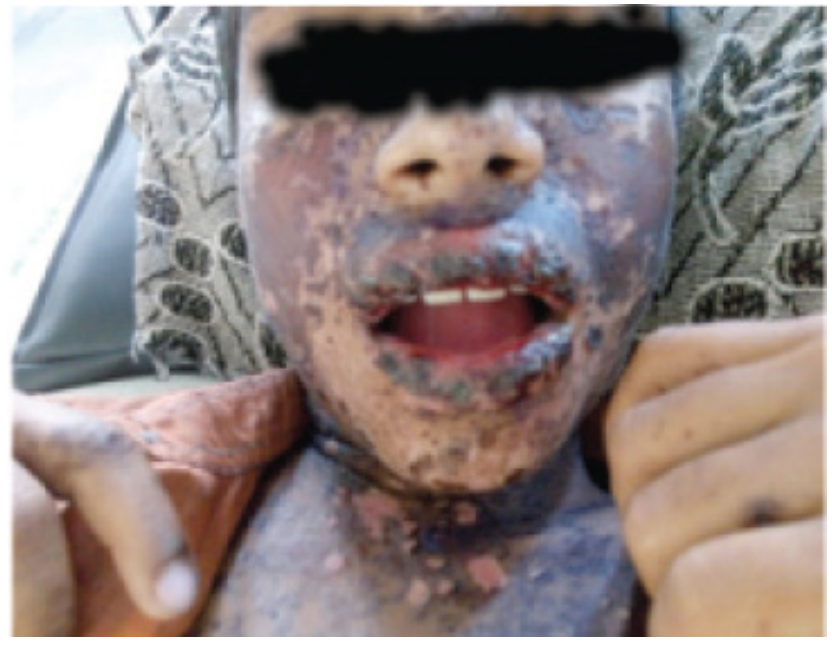

Conjunctivitis, Angioedema and Crustations on Angle of mouth

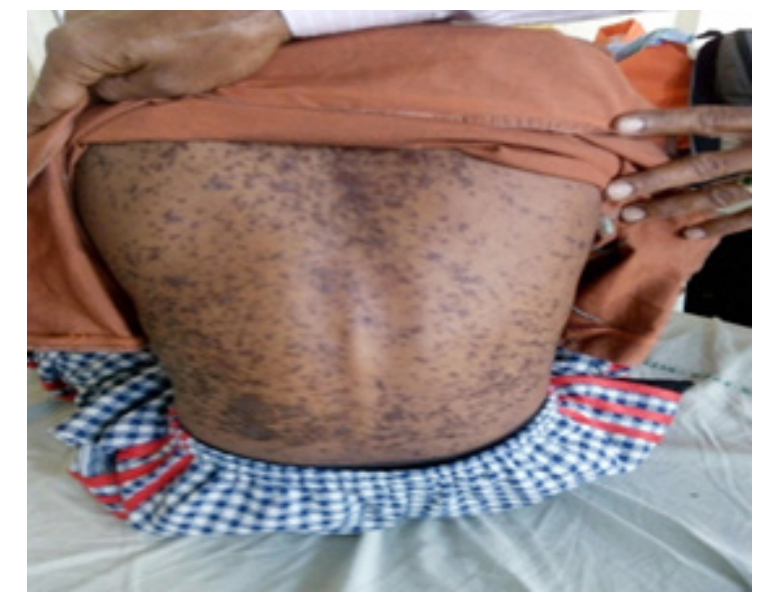

Maculopapular Rashes

days ago. The next day he developed conjunctivitis and angioedema and one day later the patient presented with the erythematous lesions all over the body, oral ulcers and crustations on the angle of mouth for which he was taken to the hospital. On general examination, his vitals were: Temperature $99^{\circ} \mathrm{F}$, Pulse rate $88 / \mathrm{min}$, Blood pressure 100/70 mmHg and Respiratory rate 28/ min. Total body surface area involvement of lesions was about 60\%. Laboratory investigations revealed elevated level of Erythrocyte Sedimentation Rate $(60 \mathrm{~mm} / \mathrm{hr})$ depicting inflammatory condition. On evaluation of medication history, the patient was found to be a newly diagnosed Epileptic since last one month and he was on carbamazepine $100 \mathrm{mg}$ for seizures. On $8^{\text {th }}$ day of carbamazepine therapy, the child developed erythematous lesions and macular rashes all over the body with gradual increase to $60 \%$ of body surface area. Carbamazepine was discontinued. Hence, final diagnosis was made as Carbamazepine induced Stevens - Johnson syndrome.

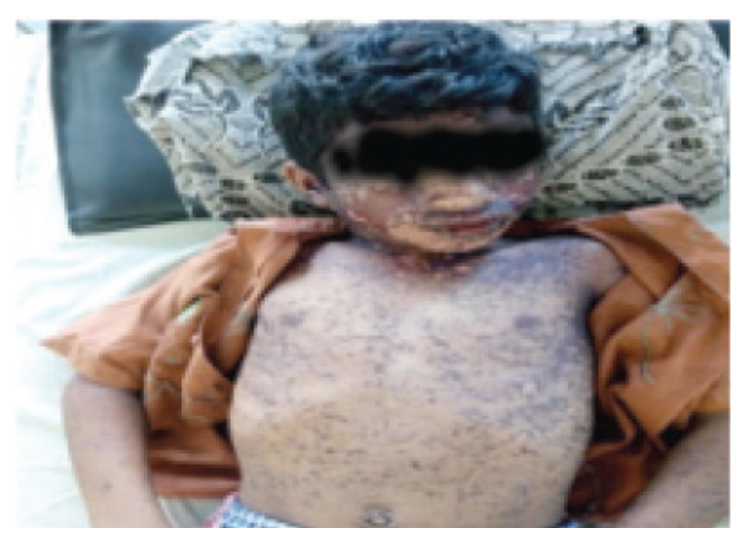

Erythematous Lesions on Face

Patient was treated with Dexamethasone and cefotaxime parenterally, Betamethasone topically, clotrimazole mouth paint, chlorhexidine mouth wash for oral ulcers, tobramycin eye drops for eye lesion, along with IV fluids and other supportive measures. Finally the patient improved and was discharged after 7 days of hospital stay. The patient's attenders were counselled regarding the condition of the patient and his discharge medications were Tab Prednisolone 20mg OD and Tab Ranitidine 150 mg BD (1/2) and creams for local application.

\section{DISCUSSION}

There are random reports of SJS with the use of CBZ. Approximately three persons per million per week may experience life-threatening dermatological syndromes with the use of CBZ. ${ }^{3}$ Patient developed itchy erythematous lesions and macular rashes 7 days after consumption of carbamazepine $100 \mathrm{mg}$. It is a delayed type of hypersensitivity reaction. A case-control study reported that the short term use of carbamazepine increases the risk of SJS for a period of less than 8 weeks. In such case, the offending drug should be withdrawn. ${ }^{4}$

The time between the $1^{\text {st }}$ administration and development of SJS/TEN is $1-4$ weeks in majority of the cases. ${ }^{5}$ Early use of short term dexamethasone therapy seems beneficial. Short term dexamethasone therapy $(1.5 \mathrm{mg} /$ $\mathrm{kg} /$ day) on three consecutive days at an early stage of the reaction may benefit the patient. A recent systematic review in children has shown the beneficial effect of steroids. ${ }^{6}$ In our case, IV dexamethasone therapy proved to be effective.

A causality analysis was done using the Naranjo's 
algorithm, ${ }^{7}$ WHO-UMC Scale and the present ADR was found to be 'PROBABLE' with carbamazepine. The reaction was "PROBABLY PREVENTABLE" according to the modified Schumock and Thornton scale and the modified Hartwig and Siegel severity ${ }^{8}$ scale showed that the reaction was SEVERE (Level 6).

\section{PATIENT ALERT CARD}

Alert card was issued to the patient attenders and was advised to reveal this medication allergy to the other physicians before getting prescription from them to avoid this drug which causes SJS or TEN.

\section{PATIENT ASCENT FORM}

Written informed Ascent form was taken from the patient attenders for the presentation/publication of the case report.

\section{CONCLUSION}

Adverse drug reactions in a paediatric population is an important concern. So, rigid ADR monitoring among paediatric patients is necessary to ensure safety of drug therapy. Patient Care should be taken while prescribing drug, as Carbamazepine is well reported in literature for causing SJS and should be counselled about the possible side effects. Therefore, Carbamazepine must not be rechallenged so as to avoid further fatal reactions. Early diagnosis helps to prevent secondary infections and subsequent complications. Pharmacovigilance which deals with the identification, assessment and prevention of ADRs can help in providing continuous information on medication safety and appropriate use.

\section{REFERENCES}

1. Swapnil SD, Rishikesh CD, Aarti MM, Vaishali VS. Drug Induced - Stevens Johnson Syndrome: A Case Report. International Journal of Scientific Study. 2014;2(4): 84-7

2. Suneet KU, Rangeel SR, Archana S, Vijay T, Deepak D. Carbamazepineinduced erythema multiforme major in an epileptic patient with bipolar affective disorder. Journal of Pharmacology and Pharmacotherapeutics. 2012;3(2):2024

3. Sadock BJ, Sadock VA. Carbamazepine. In: Kaplan and Sadock's Synopsis of Psychiatry: Behavioral. Sciences/Clinical Psychiatry. $9^{\text {th }}$ ed. Philadelphia: Lippincott Williams and Wilkins. 2003;1036-9.

4. Rzany B, Correia O, Kelly JP, Naldi L, Auquier A, Stern R. Risk of StevensJohnson syndrome and toxic epidermal necrolysis during first weeks of antiepileptic therapy: A casecontrol study. Study Group of the International Case Control Study on Severe Cutaneous Adverse Reactions. Lancet. 1999;353(9171):21904.

5. Sanmarkan AD, Sori T, Thappa DM, Jaisankar TJ. Retrospective analysis of stevensjohnson syndrome and toxic epidermal necrolysis over a period of 10 years. Indian J Dermatol. 2011;56(1):259.

6. Sew KT, Yong KT. Profile and Pattern of Stevens - Johnson syndrome and Toxic Epidermal Necrolysis in a General Hospital in Singapore: Treatment Outcomes. Acta Derm Venereol. 2011;91(1):62-6.

7. Naranjo CA, Busto U, Sellers EM, Sandor P, Ruiz I, Roberts EA, et al. A method for estimating the probability of adverse drug reactions. Clin Pharmacol Ther. 1981;30(2):239-45.

8. Srinivasan R, Ramya G. Adverse Drug Reaction - Causality Assessment. IJRPC. 2011;1(3):606-12. 